\title{
What Does GABAergic Neurotransmission System Do in Acupuncture Analgesia?
}

\author{
Yinfang Xu1,2 \\ ${ }^{1}$ Shanghai Key Laboratory of Acupuncture Mechanism and Acupoint Function, Fudan University, Shanghai, China \\ ${ }^{2}$ Shanghai Research Center of Acupuncture and Meridians, Shanghai, China \\ Email: annxu21@hotmail.com
}

How to cite this paper: $\mathrm{Xu}$, Y.F. (2017) What Does GABAergic Neurotransmission System Do in Acupuncture Analgesia? Journal of Biosciences and Medicines, 5, 61-70. https://doi.org/10.4236/jbm.2017.53007

Received: December 16, 2016

Accepted: March 19, 2017

Published: March 22, 2017

Copyright (c) 2017 by author and Scientific Research Publishing Inc. This work is licensed under the Creative Commons Attribution International License (CC BY 4.0).

http://creativecommons.org/licenses/by/4.0/

\begin{abstract}
As one of the essential components of traditional Chinese medicine, acupuncture has been accepted world-widely for its effectiveness in treating various disease and health conditions. Pain management is one of the least controversial therapeutic benefits of acupuncture treatment. To date, the mechanism underlying acupuncture analgesia remains poorly understood. In this review, roles of members of GABAergic neurotransmission system which has long been related to pain perception and modulation, in acupuncture analgesia are discussed.
\end{abstract}

Keywords

GABAergic Neurotransmission System, Acupuncture, Acupuncture Analgesia

\section{Introduction}

Acupuncture is an important therapeutic method of traditional Chinese medicine (TCM). The clinical practice of acupuncture in China can be traced back to at least 2500 years ago. As a complementary and alternative medicine, it is also becoming more and more popular in many other countries [1] [2] [3] [4]. During traditional acupuncture treatment, experienced acupuncturist inserts the fine acupuncture needles, typically made of stainless steel, into certain acupuncture points (also known as acupoints) according to the symptoms of patients. After the insertion, acupuncturist applies lifting-thrusting and twisting-rotating manipulation to stimulate the acupoints and guide the flow of Qi. Such procedure has been recognized to be effective for a wide range of health conditions, including chronic low back pain, neck and shoulder stiffness, visceral pain, migraine, osteoarthritis, postoperative nausea and vomiting [5] [6] [7] [8] [9].

According to TCM theories, acupuncture manipulation can dredge the meri- 
dians, promote the circulation of Qi and Xue, and maintain the Yin and Yang in harmony, which eventually alleviates different symptoms. Up to date, however, it is still difficult to define the terms, such as $Q i$, meridian or acupoint, using established concepts of mainstream Western medicine. TCM theories endowed acupuncture with mysteriousness, but also held back the recognition and attractiveness of this technique. The TCM communities, therefore, are putting numerous efforts to explore the mechanisms underlying acupuncture and describe that with unambiguous scientific concepts. Such interpretation will not only increase the attractiveness of acupuncture to those in need, also improve this ancient technique.

Over the past several decades, experimental biologists, chemists, biophysicists and physiologists have begun to unravel the mystery of acupuncture mechanisms. Since pain relief is one of the well-accepted therapeutic benefits of acupuncture treatment, numerous efforts have been made to elucidate the mechanisms underlying acupuncture analgesia. As is well known, pain perception and modulation is a sophisticated process participated by both the glutamatergic and the GABAergic systems [10] [11] [12]. Hence, involvement of these neuronal systems has been considered as a possible mechanism of acupuncture analgesia [13] [14]. In this review, progresses in unravelling mechanisms of GABAergic neurotransmission system involved in acupuncture analgesia will be discussed.

\section{Acupuncture Analgesia}

The International Association for the Study of Pain (IASP) defines pain as "an unpleasant sensory and emotional experience associated with actual or potential tissue damage, or described in terms of such damage". Oftentimes, pain indicates the "actual or potential tissue damage" and thus serves as an alert, which motivates the individual to look for and take care of the cause of the damage. Under some pathological conditions, however, paingoes on for weeks, months or even years, and dramatically reduces life quality of patients. Hence, pain management has long been an important branch of medicine, which aims at easing the intensity of pain or unpleasantness.

Drugs such as analgesics and anxiolytics are commonly employed by physicians to achieve pain relief. Those drugs, while very effective, oftentimes have undesired side effects including nausea, vomiting and addiction. Therefore, non-pharmacologic therapies with less adverse effects, such as application of ice/heat, acupuncture and massage, are often utilized for pain management.

According to the National Center for Complementary and Integrative Health (NCCIH) of the National Institutes of Health (NIH)

(https://nccih.nih.gov/health/acupuncture/introduction), acupuncture may help ease types of pain that are often chronic such as low-back pain, neck pain, and osteoarthritis/knee pain. It also may help reducing the frequency of tension headaches and prevent migraine headaches. Therefore, more and more people suffering from pain, especially these types of chronic pain, are advised to consider using acupuncture as an alternative treatment. Meanwhile, numerous ef- 
forts are being made to unravel the mechanisms underlying acupuncture analgesia [15].

\section{GABAergic Neurotransmission System \& Pain}

Gamma-aminobutyric acid (GABA) is a non-proteinogenic amino acid acting as the predominant inhibitory neurotransmitter in the adult mammalian central nervous system (CNS). Figure 1 illustrates the produce, release, action and reuptake of GABA at atypical GABAergic synapse in adult mouse CNS. GABA are synthesized and stored in vesicles in the presynaptic neurons at resting state. When the action potential arrives at the presynaptic nerve ending, voltage-dependent $\mathrm{Ca}^{2+}$ channels are opened. The channel opening causes the elevation of intracellular $\mathrm{Ca}^{2+}$, and subsequently induces the fusion of synaptic vesicles with the presynaptic membrane at active zones; the GABA-loaded vesicles then release their contents into the synaptic cleft. The GABA molecules diffuse across the cleft, bind to GABA receptors (GABARs), which are located on the postsynaptic membrane. The activation of the GABARs reduces intrinsic electrical activity and excitability of the postsynaptic neuron. Thereafter, to terminate the neurotransmission, the released neurotransmitter molecules are rapidly removed by highly efficient GABA transporters located on the presynaptic terminal and surrounding glial cells.

Before the discovery of neurons and the way they conduct and interpret signals, pain was believed to be one of the emotions. The first modern pain theory introduced by Melazck and Wall in 1965 [16] offered a physiological explanation for pain perception. This so-called "gate control" theory asserts that, at the level of spinal cord, the activation of non-nociceptive fibers can interfere with signals from afferent pain-receptivenerves (pain fibers) through exciting the inhibitory interneurons, thus "close the gate" and inhibit pain. Meanwhile, the activation of pain fibers can also impede the inhibitory interneurons to "open the gate" and transmit pain stimuli to higher CNS area. Hence, proper processing of nocicep-

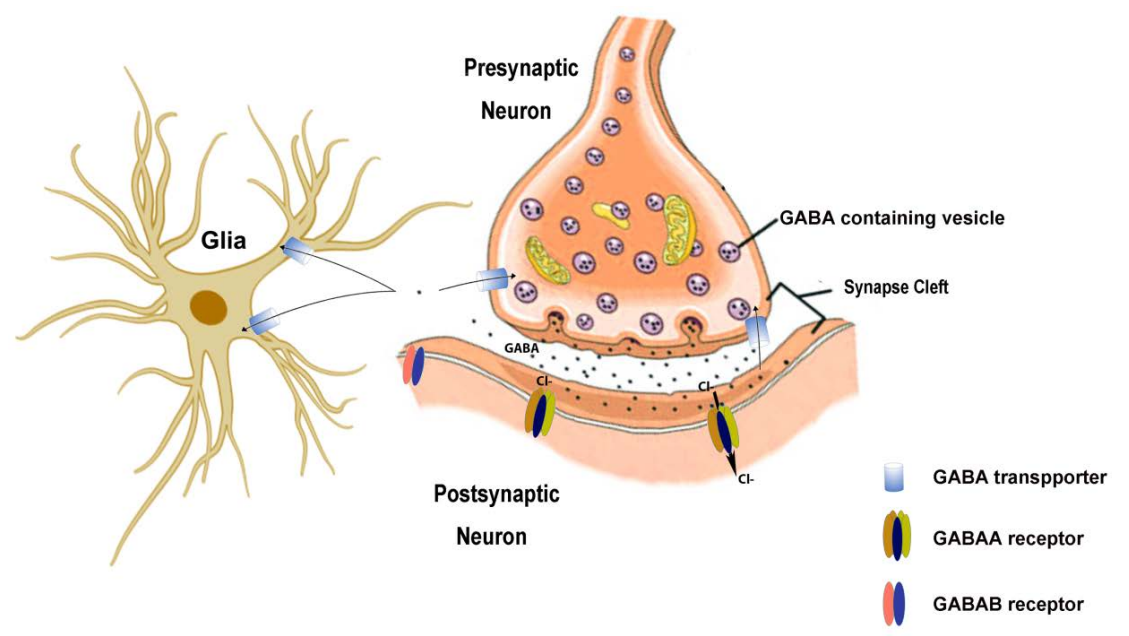

Figure 1. Scheme of the production, release, action and reuptake of GABA at a GABAergic synapse in adult mouse CNS. 
tivesignal depends critically on the function of inhibitory interneuron.

Since GABAergic neurons are the predominant inhibitory interneurons and widely distributed throughout the mammalian CNS, members of GABAergic neurotransmission system have long been researchtargets for understanding pain perception and modulation [10] [17] [18]. Intrathecal injection of GABA right after nerve injury was reported to permanently reverse neuropathic pain, suggesting that altered spinal GABA levels may contribute to the induction phase of chronic neuropathic pain [19]. Different types of $\mathrm{GABA}_{\mathrm{A}}$ receptors have been found to be involved in pre- and postsynaptic inhibition, which contributes to physiological and pathological pain sensation [20] [21] [22]. Both behavioral and electrophysiological evidence show that administration of $\mathrm{GABA}_{\mathrm{A}}$ or $\mathrm{GABA}_{\mathrm{B}}$ receptor agonists can attenuate central neuropathic pain after spinal cord injury in rat. On the other hand, spinal administration of the antagonist for GABA receptors produces hyperalgesia in normal rats [23] [24]. Transgenic mice with overexpressed GABA transporter 1 (GAT1) exhibited significant hyperalgesia after nociceptive stimuli [25], while GAT1 knockout mice show markedly increased pain threshold [26]. Both of those two genetically modified animal models confirmed that GAT1 plays a vital role in pain modulation.

\section{GABAergic Neurotransmission System \& Acupuncture Analgesia}

As soon as people became aware of the necessity of translating the terms of TCM into modern concepts of medicine, exploring the role of the GABAergic neurotransmission system in acupuncture-induced analgesia became a promising starting point for understanding the underlying mechanisms of AA.

\subsection{Role of GABA in AA}

Since GABA itself has been recognizedas a natural painkiller, researchers have been applying this molecule at the central nerve structures that participate in pain modulation to examine its role in AA. Gao et al. [27] reported thatapplying electro-acupuncture (EA) at "Zusanli" (ST36) and "Huantiao" (GB 30) acupoints can inhibit the responses of most periaqueductal gray (PAG) neurons evoked by noxious stimulation. Such acupuncture effect, however, abolished when GABA was topically administrated on frontal cortex. Those observations are probably among the earliest which suggested the involvement of GABAergic transmission in AA.

Yan and colleagues [28] investigated the analgesia effect of EA on rats with neuropathic pain, and its underlying mechanisms. They compared the changes of neurotransmitter contents in the lumbar spinal cord of control and chronic constrictive injury (CCI) model, before and after EA treatment. Performing EA at "Huantiao" (GB 30) and "Weizhong" (BL 40) significantly reduced the release of excitatory amino acid, but increased the release of inhibitory neurotransmitter, especially GABA. Hence, increased GABAergic activity may closely be asso- 
ciated with the observed pain relief in CCI rats.

\subsection{Role of GABA Receptors in AA}

There are two classes of GABA receptors, the ionotropic $\mathrm{GABA}_{\mathrm{A}}$ receptors and the metabotropic $\mathrm{GABA}_{\mathrm{B}}$ receptors. $\mathrm{GABA}_{\mathrm{A}}$ receptors are ligand-gated ion channels composed of five subunits, likely two $\alpha$, one $\beta$ and two $\gamma$ subunits. Those subunits are assembled so that a channel is formed at the center of the complex [29]. Binding of GABA or GABA-like molecules to the $\mathrm{GABA}_{\mathrm{A}}$ receptor can trigger the temporarily opening of the channel, which allows the inward flow of chloride ions $\left(\mathrm{Cl}^{-}\right)$, and thus decreases the excitability of the postsynaptic neuron. $G_{A B A_{B}}$ receptors [30] are heterodimers composed of $G_{A B A}$ and $G_{B B A}$ subunits, and $\mathrm{GABA}_{\mathrm{B} 1}$ subunit has two isoforms, $\mathrm{GABA}_{\mathrm{Bla}}$ and $\mathrm{GABA}_{\mathrm{B1b}}$. Activation of the $\mathrm{GABA}_{\mathrm{Bla} / \mathrm{B} 2}$ heterodimer, which is generally believed to be localized to presynaptic neurons, can decrease GABA release by inhibiting voltage-gated $\mathrm{Ca}^{2+}$ channels and vesicular release. Activation of postsynaptically localized $\mathrm{GABA}_{\mathrm{Blb} / \mathrm{B} 2}$, however, can cause postsynaptic inhibitionvia modulating $\mathrm{Ca}^{2+}$ channels and $\mathrm{G}$ protein-coupled potassium $\left(\mathrm{K}^{+}\right)$channels [31] [32].

Brain region-specific alteration in GABAR subunit expression was attributed to AA effects by Gao and the colleagues [33]. It was reported that EA treatment at "Futu" (LI 18) and "Hegu" (LI 4)-"Neiguan" (PC 6) can significantly suppress the formalin-injection-induced pain reactions in the thyroid region. Further investigations show that the expression level of some $\mathrm{GABA}_{\mathrm{A}}$ and $\mathrm{GABA}_{\mathrm{B}}$ subunits were significantly higher in the LI 18 and LI 4-PC 6 groups than in the nontreated model group, suggesting that AA effects are associated with the upregulation of GABA receptors function in this area.

Involvement of GABARs in AA was often indirectly tested by the effects of GABAR agonists and antagonists on acupuncture-induced analgesia. Locally applied bicuculline, a $\mathrm{GABA}_{\mathrm{A}}$ receptor-selective antagonist, was found to reduce the EA-induced enhancement of presynaptic depolarization of primary C-afferents [34]. Silva et al. [35] discovered that the duration of both low $(2-\mathrm{Hz})$ and high frequency $(100-\mathrm{Hz})$ EA induced analgesia (EAIA) based on mechanisms that involve spinal $\mathrm{GABA}_{A}$ and $\mathrm{GABA}_{\mathrm{B}}$ receptors. In particular, the $\mathrm{GABA}_{\mathrm{B}}$ receptor is involved in the intensity of $100-\mathrm{Hz}$ EA-induced analgesia. Later on, the same group also found that 2-Hz EAIA utilizes $\mathrm{GABA}_{\mathrm{A}}$ mechanism in the dorsal anterior pretectal nucleus $(\mathrm{dAPtN})$, a midbrain structure participates in antinociception [36] [37]. On the contrary, pre-administration of diazepam, an $\alpha 1$ subunit specific agonist of $\mathrm{GABA}_{\mathrm{A}}$ receptor, can disinhibit EA-induced inhibition of GABAergic activity in the thalamus and pons-medulla regions [38] [39].

\subsection{Role of GABA Transporters in AA (Including Role of DOR in AA in This Part)}

GABAergic neurotransmission is a fast synaptic transmission, which requires a precise control of the timing of GABA release, GABA receptor activation, and GABA clearance from synaptic cleft as well. Apart from diffusion, GABA clear- 
ance from the extracellular space relies mainly on rapid uptake, which accomplished by the GABA transporterslocalized to presynaptic nerve terminals and surrounding glia. GABA transporters belong to a large family of sodium- and chloride-dependent transporter proteins. To date, four transporters with varying affinities for GABA (termed GAT1, GAT2, GAT3 and BGT1) have been identified in mammalian CNS [40]-[45]. GAT1, the most abundant transporter, contributes $75 \%-80 \%$ of GABA uptake and plays a crucial role in maintaining low and non-toxic extracellular GABA concentration, and thus the fine tuning of GABAergic neurotransmission [46].

Malfunction of GAT1 has been related to altered pain threshold in genetically modified mice [25] [26]. Although there is no direct proof of GAT1 being involved in AA, evidence has shed lights on such possibility. Studies have shown that acupuncture treatment can stimulate the release of endogenous opioid neuropeptides (also known as endorphins) and applying opioid receptor inhibitor can block acupuncture-induced analgesia, suggesting the involvement of endogenous opioids in AA [47] [48] [49] [50]. Two of the four discovered endorphins, enkephalin and $\beta$-endorphin, are recognized as agonists for DOR. Utilizing Xenopus oocytes as a model system, $\mathrm{Pu}$ and coworkers [51] [52] have shown that co-expression of delta-opioid receptor (DOR) as well as DOR activation significantly reduced the number of functional GAT1, the rate of GABA uptake and GAT1-mediated current. Besides, rats chronically treated with morphine exhibited reduced GABA uptake, as well as GAT1-mediated current. Therefore, it is quite likely that the regulation of GAT1 activity by DOR stimulation participates in AA as well. A preliminary study in our lab shows that EA treatment may down-regulate the elevated GAT1 expression level in the spinal cord of chronic constriction injury (CCI) mice.

\section{Conclusion}

The current research supports the view that acupuncture treatment may help to achieve satisfactorily analgesia. In contrast to pharmacological treatment, acupuncture may minimize unwanted side effects. Understanding the mechanisms of acupuncture-induced analgesia will not only encourage more people suffering from pain to try and benefit from acupuncture treatment, also help developing this esoteric technique. In this review, experimental findings showing the involvement of the GABAergic neurotransmission system in acupuncture analgesia are discussed. Although not many biological experiments have been carried out so far, these findings demonstrated that acupuncture, the ancient TCM technique, may share similar mechanisms with modern pain relief methods.

\section{Acknowledgements}

The author wishes to express her sincere appreciation to Prof. W. SCHWARZ for providing valuable advice. This work was supported by the National Natural Science Foundation of China (No. 81403489 to Y. Xu), the Shanghai Key Laboratory of Acupuncture Mechanism and Acupoint Function (14DZ2260500), the 
National Basic Research Program of China (973 Program 2012CB518502), and Green Valley Holding Co.

\section{Conflict of Interests}

The author declares that there is no conflict of interests regarding the publication of this paper.

\section{References}

[1] Xia, Y., Ding, G. and Wu, G.C. (2012) Current Research in Acupuncture. Springer, New York.

[2] Eisenberg, D.M., Kessler, R.C., Foster, C., Norlock, F.E., Calkins, D.R. and Delbanco, T.L. (1993) Unconventional Medicine in the United States. Prevalence, Costs, and Patterns of Use. The New England Journal of Medicine, 328, 246-252. https://doi.org/10.1056/NEJM199301283280406

[3] Cherkin, D.C., Deyo, R.A., Sherman, K.J., Hart, L.G., Street, J.H., Hrbek, A., Davis, R.B., Cramer, E., Milliman, B., Booker, J., Mootz, R., Barassi, J., Kahn, J.R., Kaptchuk, T.J. and Eisenberg, D.M. (2002) Characteristics of Visits to Licensed Acupuncturists, Chiropractors, Massage Therapists, and Naturopathic Physicians. The Journal of the American Board of Family Practice, 15, 463-472.

[4] Kaptchuk, T.J. (2002) Acupuncture: Theory, Efficacy, and Practice. Annals of Internal Medicine, 136, 374-383. https://doi.org/10.7326/0003-4819-136-5-200203050-00010

[5] Berman, B.M., Langevin, H.M., Witt, C.M. and Dubner, R. (2010) Acupuncture for Chronic Low Back Pain. The New England Journal of Medicine, 363, 454-461. https://doi.org/10.1056/NEJMct0806114

[6] Vickers, A.J., Cronin, A.M., Maschino, A.C., Lewith, G., MacPherson, H., Foster, N.E., Sherman, K.J., Witt, C.M. and Linde, K. (2012) Acupuncture for Chronic Pain: Individual Patient Data Meta-Analysis. Archives of Internal Medicine, 172, 1444-1453. https://doi.org/10.1001/archinternmed.2012.3654

[7] Shengelia, R., Parker, S.J., Ballin, M., George, T. and Reid, M.C. (2013) Complementary Therapies for Osteoarthritis: Are They Effective? Pain Management Nursing, 14, e274-e288.

[8] Wong Lit, W.D., Wang, Y., Xue, C.C., Wang, L.P., Liang, F.R. and Zheng, Z. (2015) Local and Distant Acupuncture Points Stimulation for Chronic Musculoskeletal Pain: A Systematic Review on the Comparative Effects. European Journal of Pain, 19, 1232-1247. https://doi.org/10.1002/ejp.671

[9] Cheong, K.B., Zhang, J.P., Huang, Y. and Zhang, Z.J. (2013) The Effectiveness of Acupuncture in Prevention and Treatment of Postoperative Nausea and Vomiting-A Systematic Review and Meta-Analysis. PLOS ONE, 8, e82474. https://doi.org/10.1371/journal.pone.0082474

[10] Sawynok, J. (1984) GABAergic Mechanisms in Antinociception. Progress in Neuro-Psychopharmacology \& Biological Psychiatry, 8, 581-586.

[11] Fundytus, M.E. (2001) Glutamate Receptors and Nociception: Implications for the Drug Treatment of Pain. CNS Drugs, 15, 29-58. https://doi.org/10.2165/00023210-200115010-00004

[12] Zhou, H.Y., Zhang, H.M., Chen, S.R. and Pan, H.L. (2007) Increased Nociceptive Input Rapidly Modulates Spinal GABAergic Transmission through Endogenously Released Glutamate. Journal of Neurophysiology, 97, 871-882. 
https://doi.org/10.1152/jn.00964.2006

[13] Schwarz, W. and Gu, Q. (2013) Cellular Mechanisms in Acupuncture Points and Affected Sites. In: Xia, Y., Ding, G. and Wu, G., Eds., Current Research in Acupuncture, Springer, New York, 37-51. https://doi.org/10.1007/978-1-4614-3357-6_2

[14] Liang, J. and Xia, Y. (2012) Acupuncture Modulation of Neutral Transmitters/ Modulators. In: Xia, Y., Ding, G. and Wu, G., Eds., Current Research in Acupuncture, Springer, New York, 1-36. https://doi.org/10.1007/978-1-4614-3357-6_1

[15] Hesse, T., Henkel, B., Zygmunt, M., Mustea, A. and Usichenko, T.I. (2016) Acupuncture for Pain Control after Caesarean Section: A Prospective Observational Pilot Study. Acupuncture in Medicine, 34, 14-19.

[16] Melzack, R. and Wall, P.D. (1965) Pain Mechanisms: A New Theory. Science, 150, 971-979. https://doi.org/10.1126/science.150.3699.971

[17] Enna, S.J. and McCarson, K.E. (2006) The Role of GABA in the Mediation and Perception of Pain. Advances in Pharmacology, 54, 1-27.

[18] Jasmin, L., Wu, M.V. and Ohara, P.T. (2004) GABA Puts a Stop to Pain. Current Drug Target-CNS \& Neurological Disorders, 3, 487-505. https://doi.org/10.2174/1568007043336716

[19] Eaton, M.J., Martinez, M.A. and Karmally, S. (1999) A Single Intrathecal Injection of GABA Permanently Reverses Neuropathic Pain after Nerve Injury. Brain Research, 835, 334-339.

[20] Lorenzo, L.E., Godin, A.G., Wang, F., St-Louis, M., Carbonetto, S., Wiseman, P.W., Ribeiro-da-Silva, A. and De, K.Y. (2014) Gephyrin Clusters Are Absent from Small Diameter Primary Afferent Terminals Despite the Presence of $\mathrm{GABA}_{\mathrm{A}}$ Receptors. Journal of Neuroscience, 34, 8300-8317. https://doi.org/10.1523/JNEUROSCI.0159-14.2014

[21] Paul, J., Zeilhofer, H.U. and Fritschy, J.M. (2012) Selective Distribution of GABA Receptor Subtypes in Mouse Spinal Dorsal Horn Neurons and Primary Afferents. Journal of Comparative Neurology, 520, 3895-3911. https://doi.org/10.1002/cne.23129

[22] Witschi, R., Punnakkal, P., Paul, J., Walczak, J.S., Cervero, F., Fritschy, J.M., Kuner, R., Keist, R., Rudolph, U. and Zeilhofer, H.U. (2011) Presynaptic $\alpha 2-G_{A B A}$ Receptors in Primary Afferent Depolarization and Spinal Pain Control. Journal of Neuroscience, 31, 8134-8142. https://doi.org/10.1523/JNEUROSCI.6328-10.2011

[23] Malan, T.P., Mata, H.P. and Porreca, F. (2002) Spinal GABA ${ }^{A}$ and GABA ${ }^{B}$ Receptor Pharmacology in a Rat Model of Neuropathic Pain. Anesthesiology, 96, 1161-1167. https://doi.org/10.1097/00000542-200205000-00020

[24] Gwak, Y.S., Tan, H.Y., Nam, T.S., Paik, K.S., Hulsebosch, C.E. and Leem, J.W. (2006) Activation of Spinal GABA Receptors Attenuates Chronic Central Neuropathic Pain after Spinal Cord Injury. Journal of Neurotrauma, 23, 1111-1124. https://doi.org/10.1089/neu.2006.23.1111

[25] Hu, J.H., Yang, N., Ma, Y.H., Zhou, X.G., Jiang, J., Duan, S.H., Mei, Z.T., Fei, J. and Guo, L.H. (2003) Hyperalgesic Effects of Gamma-Aminobutyric Acid Transporter I in Mice. Journal of Neuroscience Research, 73, 565-572. https://doi.org/10.1002/jnr.10677

[26] Xu, Y.F., Cai, Y.Q., Cai, G.Q., Jiang, J., Sheng, Z.J., Wang, Z.G. and Fei, J. (2008) Hypoalgesia in Mice Lacking GABA Transporter Subtype 1. Journal of Neuroscience Research, 86, 465-470. https://doi.org/10.1002/jnr.21499

[27] Gao, M., Li, Q., Zhang, J. and Liu, Y. (1990) Effect of Changing the Functional State of Frontal Cortex by GABA on the Acupuncture Effect of PAG Neurons. Acupunc- 
ture Research, 15, 264-268.

[28] Yan, L.P., Wu, X.T., Yin, Z.Y. and Ma, C. (2011) Effect of Electroacupuncture on the Levels of Amino Acid Neurotransmitters in the Spinal Cord in Rats with Chronic Constrictive Injury. Acupuncture Research, 36, 353-356, 379.

[29] Sigel, E. and Steinmann, M.E. (2012) Structure, Function, and Modulation of $\mathrm{GABA}_{\mathrm{A}}$ Receptors. The Journal of Biological Chemistry, 287, 40224-40231. https://doi.org/10.1074/jbc.R112.386664

[30] Schwenk, J., Metz, M., Zolles, G., Turecek, R., Fritzius, T., Bildl, W., Tarusawa, E., Kulik, A., Unger, A., Ivankova, K., Seddik, R., Tiao, J.Y., Rajalu, M., Trojanova, J., Rohde, V., Gassmann, M., Schulte, U., Fakler, B. and Bettler, B. (2010) Native $\mathrm{GABA}_{\mathrm{B}}$ Receptors Are Heteromultimers with a Family of Auxiliary Subunits. Nature, 465, 231-235. https://doi.org/10.1038/nature08964

[31] Foster, J.D., Kitchen, I., Bettler, B. and Chen, Y. (2013) GABA $_{B}$ Receptor Subtypes Differentially Modulate Synaptic Inhibition in the Dentate Gyrus to Enhance Granule Cell Output. British Journal of Pharmacology, 168, 1808-1819. https://doi.org/10.1111/bph.12073

[32] Heaney, C.F. and Kinney, J.W. (2016) Role of GABAB Receptors in Learning and Memory and Neurological Disorders. Neuroscience \& Biobehavioral Reviews, 63, $1-28$.

[33] Gao, Y.H., Chen, S.P., Wang, J.Y., Qiao, L.N., Han, Y.J., Lin, D., Ji, C.F., Xu, Q.L. and Liu, J.L. (2012) Effects of Electroacupuncture of "Futu" (LI 18), etc. on Pain Behavior and Expression of GABA Receptor Subunit Genes in Cervical Spinal Cord in Rats with Thyroid Regional Pain. Acupuncture Research, 37, 93-98.

[34] Li, C., Zhu, L., Li, W. and Ji, C. (1993) Relationship between the Presynaptic Depolarization Effect of Acupuncture and r-Aminobutyric Acid, Opioid Peptide and Substance P. Acupuncture Research, 18, 178-182.

[35] Silva, J.R., Silva, M.L. and Prado, W.A. (2011) Analgesia Induced by 2- or 100-Hz Electroacupuncture in the Rat Tail-Flick Test Depends on the Activation of Different Descending Pain Inhibitory Mechanisms. The Journal of Pain, 12, 51-60.

[36] Silva, M.L., Silva, J.R. and Prado, W.A. (2013) Analgesia Induced by 2- or 100-Hz Electroacupuncture in the Rat Tail-Flick Test Depends on the Anterior Pretectal Nucleus. Life Sciences, 93, 742-754.

[37] Rees, H. and Roberts, M.H. (1993) The Anterior Pretectal Nucleus: A Proposed Role in Sensory Processing. Pain, 53, 121-135.

[38] Chakrabarti, S. and Poddar, M.K. (1989) Effect of Diazepam on Electroacupuncture-Induced Changes in Regional Gamma-Aminobutyric Acid of the Rat Central Nervous System. Neuroscience Research, 7, 24-32.

[39] Rudolph, U., Crestani, F., Benke, D., Brunig, I., Benson, J.A., Fritschy, J.M., Martin, J.R., Bluethmann, H. and Mohler, H. (1999) Benzodiazepine Actions Mediated by Specific Gamma-Aminobutyric Acid $_{\mathrm{A}}$ Receptor Subtypes. Nature, 401, 796-800. https://doi.org/10.1038/44579

[40] Liu, Q.R., Lopez-Corcuera, B., Mandiyan, S., Nelson, H. and Nelson, N (1993) Molecular Characterization of Four Pharmacologically Distinct Gamma-Aminobutyric Acid Transporters In Mouse Brain [Corrected]. The Journal of Biological Chemistry, 268, 2106-2112.

[41] Lopez-Corcuera, B., Liu, Q.R., Mandiyan, S., Nelson, H. and Nelson, N. (1992) Expression of a Mouse Brain cDNA Encoding Novel Gamma-Aminobutyric Acid Transporter. The Journal of Biological Chemistry, 267, 17491-17493.

[42] Radian, R., Bendahan, A. and Kanner, B.I. (1986) Purification and Identification of 
the Functional Sodium- and Chloride-Coupled Gamma-Aminobutyric Acid Transport Glycoprotein from Rat Brain. The Journal of Biological Chemistry, 261, 1543715441.

[43] Borden, L.A., Smith, K.E., Hartig, P.R., Branchek, T.A. and Weinshank, R.L. (1992) Molecular Heterogeneity of the Gamma-Aminobutyric Acid (GABA) Transport System. Cloning of Two Novel High Affinity GABA Transporters from Rat Brain. The Journal of Biological Chemistry, 267, 21098-21104.

[44] Borden, L.A., Dhar, T.G., Smith, K.E., Branchek, T.A., Gluchowski, C. and Weinshank, R.L. (1994) Cloning of the Human Homologue of the GABA Transporter GAT-3 and Identification of a Novel Inhibitor with Selectivity for This Site. Receptors and Channels, 2, 207-213.

[45] Borden, L.A., Smith, K.E., Gustafson, E.L., Branchek, T.A. and Weinshank, R.L. (1995) Cloning and Expression of a Betaine/GABA Transporter from Human Brain. Journal of Neurochemistry, 64, 977-984. https://doi.org/10.1046/j.1471-4159.1995.64030977.x

[46] Jensen, K., Chiu, C.S., Sokolova, I., Lester, H.A. and Mody, I. (2003) GABA Transporter-1 (GAT1)-Deficient Mice: Differential Tonic Activation of $\mathrm{GABA}_{\mathrm{A}}$ versus $\mathrm{GABA}_{\mathrm{B}}$ Receptors in the Hippocampus. Journal of Neurophysiology, 90, 26902701. https://doi.org/10.1152/jn.00240.2003

[47] Mayer, D.J., Price, D.D. and Rafii, A. (1977) Antagonism of Acupuncture Analgesia in Man by the Narcotic Antagonist Naloxone. Brain Research, 121, 368-372.

[48] Pomeranz, B. and Chiu, D. (1976) Naloxone Blockade of Acupuncture Analgesia: Endorphin Implicated. Life Sciences, 19, 1757-1762.

[49] Cheng, R.S. and Pomeranz, B. (1979) Electroacupuncture Analgesia Could Be Mediated by at Least Two Pain-Relieving Mechanisms; Endorphin and Non-Endorphin Systems. Life Sciences, 25, 1957-1962.

[50] Han, J.S. (2004) Acupuncture and Endorphins. Neuroscience Letters, 361, 258-261.

[51] Pu, L., Xu, N., Xia, P., Gu, Q., Ren, S., Fucke, T., Pei, G. and Schwarz, W. (2012) Inhibition of Activity of GABA Transporter GAT1 by Delta-Opioid Receptor. Evidence-Based Complementary and Alternative Medicine, 2012, Article ID: 818451. https://doi.org/10.1155/2012/818451

[52] Pu, L., Xu, Y. and Schwarz, W. (2015) Regulation of Membrane Transporters by Delta-Opioid Receptors. In: Xia, Y., Ed., Neural Function of the Delta-Opioid Receptor, Springer, Berlin, 349-362. https://doi.org/10.1007/978-3-319-25495-1_7 
Submit or recommend next manuscript to SCIRP and we will provide best service for you:

Accepting pre-submission inquiries through Email, Facebook, LinkedIn, Twitter, etc. A wide selection of journals (inclusive of 9 subjects, more than 200 journals)

Providing 24-hour high-quality service

User-friendly online submission system

Fair and swift peer-review system

Efficient typesetting and proofreading procedure

Display of the result of downloads and visits, as well as the number of cited articles Maximum dissemination of your research work

Submit your manuscript at: http://papersubmission.scirp.org/

Or contact jbm@scirp.org 